\begin{tabular}{|l|l|l|l|l|}
\hline \multirow{2}{*}{ aptara } & LANG & lang_604 & Dispatch: 9-4-2010 & CE: N/A \\
\cline { 2 - 5 } & Journal & MSP No. & No. of pages: 28 & PE: Matthew \\
\hline
\end{tabular}

Language Learning ISSN 0023-8333

\title{
Brain Potentials Reveal Discrete Stages of L2 Grammatical Learning
}

\author{
Judith McLaughlin \\ University of Washington \\ Darren Tanner \\ University of Washington \\ Ilona Pitkänen \\ University of Washington \\ Cheryl Frenck-Mestre \\ CNRS, Laboratoire Parole et Langage Aix-Marseille Université
}

\section{Kayo Inoue}

University of Washington

\section{Geoffrey Valentine}

University of Washington

\section{Lee Osterhout}

University of Washington

In this article we review several studies investigating the neural correlates of secondlanguage (L2) grammatical learning in the context of novice adult learners progressing through their first year of L2 classroom instruction. The primary goal of these studies was to determine how and when learners incorporate L2 knowledge into their online language processing system. We show that at least some learners progress through

Preparation of this article was supported by grant RO1 DC01947 from the National Institute on Deafness and Other Communication Disorders. The authors thank Julia Herschensohn for her comments and collaboration.

Correspondence concerning this article should be addressed to Judith McLaughlin, Department of Psychology, University of Washington, Box 351525, Seattle, WA 98195. Internet: giuditta@u.washington.edu 
discrete stages of grammatical learning during the first year of instruction. These stages are robust across languages, experimental tasks, and levels of language (lexical vs. sentential) and indicate that there is an intermediate stage of learning between no L2 grammatical knowledge and grammaticalization. We also show that although learners' brain responses are quite variable, this variability is highly systematic and can be used to identify meaningful subgroups of learners.

\section{Introduction}

The task facing any language learner is enormous. Among other tasks, learners must acquire a vast lexicon (i.e., a set of sound/meaning pairings that are largely arbitrary) and simultaneously acquire a set of well-formedness constraints (i.e., rules) that apply at multiple levels, including morphemic, lexical, and sentential. For the adult second-language (L2) learner, this task is complicated by the fact that the emerging L2 system must be integrated with an already established native (L1) linguistic system. Traditionally, research on L2 acquisition has focused on the question of ultimate attainment (e.g., Birdsong, 1992; Han \& Odlin, 2006; Hopp, 2007; Lardiere, 2007), what may or may not be acquirable in an L2 (e.g., Hawkins \& Franceschina, 2004), and whether the acquisition of certain L2 features are subject to a putative critical period for language acquisition (e.g., Birdsong, 1999; Birdsong \& Molis, 2001; Hyltenstam \& Abrahamsson, 2003; Johnson \& Newport, 1989; Singleton \& Lengyel, 1995). Much less research, however, has focused on the early stages of L2 learning. Most of the existing psycholinguistic literature on the early stages of natural language learning in adults has focused on the linguistic knowledge underlying L2 production (Schwartz \& Sprouse, 1996; Vainikka \& Young-Scholten, 1996; see White, 2003, for a review) while neglecting the development of learners' comprehension mechanisms. However, there is strong evidence showing that at least for L1 learning, comprehension precedes production (e.g., Hirsh-Pasek \& Golinkoff, 1996). Investigating the mechanisms underlying L2 comprehension during the earliest stages of L2 learning has been the focus of much of our research. In this article we review some of our findings and discuss their implications for how learners acquire rulelike aspects of their L2 in a realworld classroom environment.

In order for a measure of comprehension to be a useful tool in studying the types of knowledge a learner has acquired, it would ideally be differentially sensitive to multiple levels of linguistic processing. Furthermore, traditional research in L2 comprehension has used metalinguistic grammaticality judgments 
or sentence interpretation tasks. Although useful in studying a learner's linguistic competence, these measures are insensitive to how the learner uses the information in real time - as the person is reading or listening to the sentence. Standard measures of online processing, such as timed reading or reaction time, show whether learners experience processing difficulty, but they give little information about the nature of that difficulty. Finally, because the acquisition of L2 knowledge should be accompanied by concomitant changes in learners' neural systems, the ideal tool should be sensitive to the neural activity underlying the processing of this knowledge.

The use of event-related potentials (ERPs) meets all of these criteria; that is, they reveal online processing, differentially reflect lexical and syntactic processing, and are sensitive to developmental changes. ERPs, which reflect the synchronized postsynaptic activity in cortical pyramidal neurons, are highly sensitive to transient events in the brain and have proven to be useful tools for examining the processes involved in language comprehension. Lexical/semantic and syntactic/structural linguistic manipulations elicit qualitatively different brain responses that are characterized by distinct and consistent properties occurring over time. Lexical and semantic/conceptual manipulations such as semantic fit between a word and its preceding context (Kutas \& Hillyard, 1980), lexical status (Bentin, 1987), semantic priming (Bentin, McCarthy, \& Wood, 1985), word frequency (Barber, Vergara, \& Carreiras, 2004), and probability of occurrence within a given word string (Kutas \& Hillyard, 1984) elicit a negative deflection peaking around $400 \mathrm{~ms}$ after the presentation of a stimulus (the N400 effect). In contrast, a large positive deflection with an onset at about $500 \mathrm{~ms}$ and a duration of several hundred milliseconds (the P600 effect) is elicited by a disparate set of syntactic anomalies, including violations of phrase structure (Hagoort, Brown, \& Groothusen, 1993; Neville, Nicol, Barss, Forster, \& Garrett, 1991; Osterhout \& Holcomb, 1992), subcategorization (AinsworthDarnell, Shulman, \& Boland, 1998; Osterhout \& Holcomb, 1992; Osterhout, Holcomb, \& Swinney, 1994) and violations in agreement of number, gender, and case (Frenck-Mestre, Foucart, Carrasco, \& Herschensohn, 2009; FrenckMestre, Osterhout, J. McLaughlin, \& Foucart, 2008; Hagoort et al., 1993; Osterhout \& Mobley, 1995). Although some studies have reported an anterior negativity within a window ranging from 150 to $500 \mathrm{~ms}$ to some syntactic anomalies (the Left Anterior Negativity, or LAN: Friederici, 1995; Hahne \& Friederici, 1999; Neville et al., 1991; Osterhout \& Holcomb, 1992; Osterhout \& Mobley, 1995), the P600 effect is more reliably correlated with syntactic manipulations. These effects indicate that the brain may process meaning (N400 effect) and structural (P600/LAN effects) aspects of a language differently. ${ }^{1}$ 
Our research on L2 learning has been motivated by these findings. In the context of L2 learning, one implication is that, during comprehension, learners must somehow separate the linguistic input into those aspects related to meaning and those related to form. In other words, learners must "grammaticalize" some aspects of the L2 but not others. In our work, we define the term "grammaticalization" as the instantiation of rule-based knowledge into the learner's real-time language processing system. Once an aspect of the L2 has been grammaticalized, our assumption is that violations of that element of the grammar should elicit a P600 effect.

In our lab we have investigated some of the factors that might influence the rate and success of the grammaticalization process, specifically L1-L2 similarity and the presence of phonological cues to grammatical contrasts. In the subsequent sections, we discuss how these factors facilitate or hinder L2 acquisition, using as evidence ERP studies primarily from our lab. Then we consider the stages that learners go through to acquire fundamental knowledge structures and sets of processes that enable them to comprehend the L2.

\section{Effects of L1-L2 similarity}

There is considerable evidence that L1-L2 similarity facilitates learning at multiple levels, including lexical and grammatical aspects of an L2. Some argue that similarity allows learners to transfer their native language knowledge to their L2 (Ard \& Homburg, 1983; Hawkins \& Franceschina, 2004; Koda, 1988; MacWhinney, 2005; Odlin, 1989; Ryan \& Meara, 1991; Sabourin, Stowe, \& de Haan, 2006; Schwartz \& Sprouse, 1996). In addition, psycholinguistic studies of proficient L2 learners have demonstrated that grammatical properties of the learner's L1 can influence processing of the L2, including the computation of morphosyntactic information in real time. Violations of L2 morphosyntactic contrasts that are also expressed in the L1 elicit stronger neural and behavioral responses than those that superficially differ between the L1 and L2 (FrenckMestre et al., 2009; Jiang, 2004, 2007; Sabourin \& Haverkort, 2003; Sabourin \& Stowe, 2008; Tokowicz \& MacWhinney, 2005). A case in point is the comparison of L2 acquisition of gender concord: ERP responses to gender concord violations are found earlier for learners whose L1 has this grammatical feature than for learners whose L1 lacks it, although several factors come into play (Frenck-Mestre et al., 2009; Sabourin \& Stowe, 2008). Moreover, some argue that the emerging L2 system "piggybacks" onto the entrenched L1 system through the use of shared neural networks, which results in the transfer of processing strategies and resources (MacWhinney, 1997, 2005). 
If the rate of learning is influenced by the similarity between native and target languages, then grammatical rules that are shared between the L1 and L2 will be acquired more quickly than novel L2 rules. Furthermore, if the neural systems that are used for processing $\mathrm{L} 1$ grammar are also used to process similar rules in the L2, then L1 and L2 rule violations should elicit qualitatively similar neural responses (i.e., P600 responses). For linguistic features that are present in the L2 but absent in the L1, there is much less consensus. Some argue that grammatical features unique to the L2 are unacquirable after puberty and that learners will never show online sensitivity to these grammatical rules even at advanced levels of proficiency (Franceschina, 2005; Hawkins \& Franceschina, 2004; Jiang, 2004, 2007); a less extreme claim is that these features can be acquired, albeit more slowly than shared features (Hopp, 2007; White, 2003).

In a series of experiments we have investigated how L1-L2 similarity affects learners' acquisition and processing of rulelike aspects of their L2. One set of experiments has focused on the acquisition of morphosyntactic agreement. Here we define an agreement rule as similar when it is overtly expressed by a morphological alternation in both the L1 and L2. For example, both German and English express morphosyntactic agreement between the subject and verb; the person and number features of the subject noun phrase (NP) are realized on the verb as inflectional morphology in both languages. Although German marks more person-number contrasts than English (four unique contrasts in German vs. two in English), speakers of both languages must, nonetheless, process the agreement relationship between the subject and verb. ERP studies of agreement processing in English and German have revealed that native speakers are highly sensitive to violations of subject-verb agreement, with anomalies eliciting robust P600 effects in both languages (e.g., Osterhout \& Mobley, 1995; Rossi, Gugler, Hahne, \& Friederici, 2005). Thus, if English speakers acquiring German are able to transfer both their L1 grammatical features and processing strategies to German, then subject-verb agreement should pose no major learning obstacle and violations should elicit similar electrophysiological responses.

In a cross-sectional experiment (Tanner \& Osterhout, 2010; Tanner, Q1 Osterhout, \& Herschensohn, 2009) we recorded ERPs from learners of German at two levels of L2 experience. Participants included native German speakers $(n=13)$, native English speakers enrolled in a third-year university German course $(n=13)$, and native English speakers enrolled in a first-year university German course $(n=20)$. All learners were tested near the end of the year of instruction. Learners were presented with German sentences that were either well formed (Ich wohne in Berlin "I live in Berlin") or contained verb 
A. Native speakers

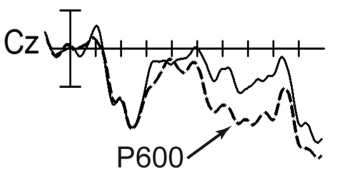

$-3 \mu \mathrm{V}$
B. Third year learners

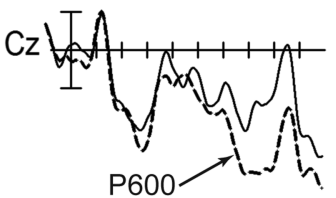

Well-formed verbs

300600900

C. First year learners

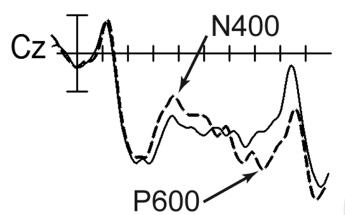

$\mathrm{P} 600$ Incorrectly inflected verbs

Figure 1 ERPs (recorded at central midline location $\mathrm{Cz}$ ) elicited by correct verb agreement (solid line) and verb agreement violations (dashed line) in (a) native German speakers, (b) English learners of German enrolled in third year university courses, and (c) English learners of German near the end of the first year of classroom instruction. Onset of the critical word (i.e., the verb) is indicated by the vertical bar. Each hash mark represents $100 \mathrm{~ms}$. The vertical calibration bar is $3 \mu \mathrm{V}$. Negative voltage is plotted up.

agreement violations ("Ich wohnt in Berlin "I lives in Berlin"). All lexical items were chosen from the first six chapters of the introductory textbook and all verbs were regular, with no stem vowel changes. The sentences were presented visually, one word at a time, and subjects were asked to make an end-of-sentence acceptability judgment from which d-prime scores were calculated. Agreement violations elicited large P600 effects in both the native German speakers and third-year learners (Figures 1a and 1b). This result is consistent with previous findings from native language processing (cf. Rossi et al., 2005) and studies of intermediate and advanced L2 learners processing grammatical features shared by their L1 and L2 (Rossi, Gugler, Friederici, \& Hahne, 2006).

First-year learners showed markedly different results. Instead of showing only a P600 effect, the grand mean waveform showed a small biphasic N400-P600 response (Figure 1c). However, this biphasic pattern was not representative of most learners' neural responses to agreement violations. Further investigation revealed that the learners showed striking individual differences in their brain responses. Whereas some learners showed primarily an N400 effect, others showed primarily a P600 effect. This finding is similar to one recently reported in a study of native Japanese speakers (Inoue \& Osterhout, 2010). These researchers found that an identical set of case-marking anomalies elicited an N400 effect in some native Japanese subjects and a P600 effect in others. Furthermore, the learners' brain responses systematically varied along the N400/P600 continuum, such that as one effect increased, the other decreased. 
Figure $2 \mathrm{a}$ shows that a similar function characterized the responses of the language learners in the present study. This function was confirmed by a reliable negative correlation between the N400 and P600 effect sizes $(r=-.62){ }^{2}$ We separated the learners into two groups based on whether they showed a larger N400 effect $(n=9)$ or a larger P600 effect $(n=11)$. Grand means for each group show that no $\mathrm{P} 600$ was present in the N400 group's waveforms and no N400 was present in the P600 group's waveforms (Figure 2b). Thus, the grand mean obscured marked and systematic individual differences in how individuals processed agreement violations. To identify the factor(s) that predicted learners' brain responses (N400 or P600), we regressed hours of instruction and d-prime score onto their N400 and P600 effect sizes. No relationship was found between these two variables and the $\mathrm{N} 400$ effect, nor was there a relationship between hours of instruction and the P600. However, there was a reliable positive correlation between d-prime scores and the P600 effect $(r=.53)$. This suggests that learners with stronger behavioral sensitivity showed a robust P600, whereas those with less behavioral sensitivity showed little or no P600.

In sum, violations of a German agreement rule produced a robust brain response in all of the German learners. However, these responses were not the same for all learners; instead, the errors produced a P600 effect in some learners and an N400 effect in others. By contrast, all of the native German speakers responded to these errors with a P600 effect. These results suggest that, at least for some learners (the N400 group), L1 knowledge and processing routines do not rapidly "transfer over" to an L2, even for aspects of the L2 that are highly similar to the L1. Moreover, because learners in this group performed less well on the conscious sentence acceptability judgment task than did the learners in the P600 group, one inference is that the type of processing used by these learners is less effective than that used by the other group. One might also infer that this differential response pattern reflects different stages of a developmental progression: Learners in an early stage of learning respond with an N400 effect to some types of grammatical errors, whereas learners in a more proficient stage respond with a more nativelike P600 effect. However, the cross-sectional nature of this experiment prohibits strong inferences about any learning discontinuities. Longitudinal experimental designs, however, might reveal qualitative changes over time in individual learners (see Osterhout, J. McLaughlin, Pitkänen, Frenck-Mestre, \& Molinaro, 2006, for a full discussion).

In several longitudinal experiments, we have tracked learners as they progress through their first year of classroom-based university L2 instruction. In one experiment (Osterhout, Frenck-Mestre, J. McLaughlin, Tanner, Q3 \& Herschensohn, 2010), ${ }^{3}$ we longitudinally followed English speakers 
A.

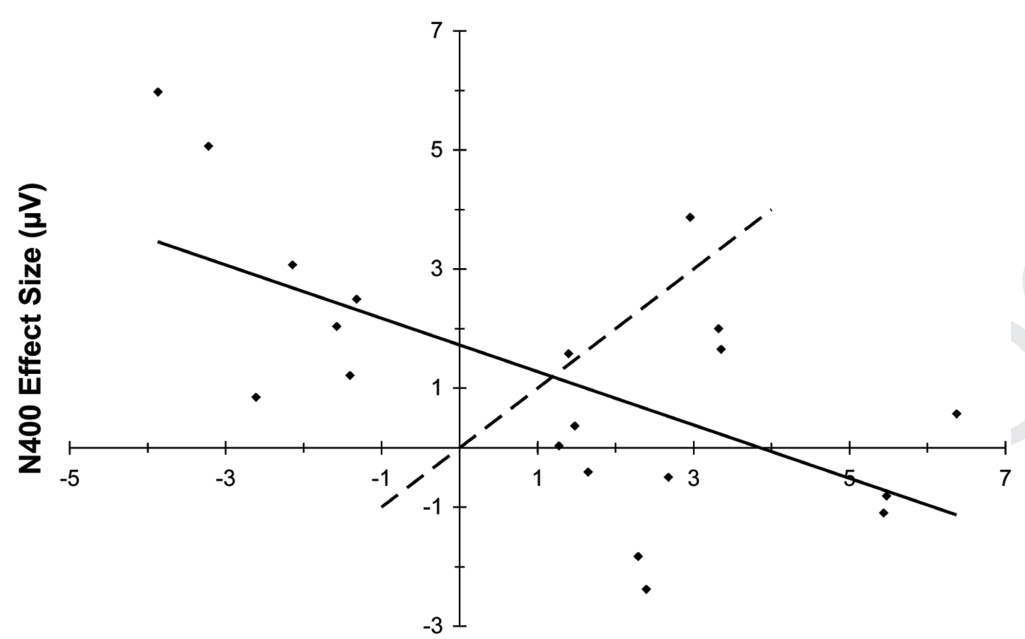

P600 Effect Size $(\mu \mathrm{V})$

B.

\section{N400 Group}
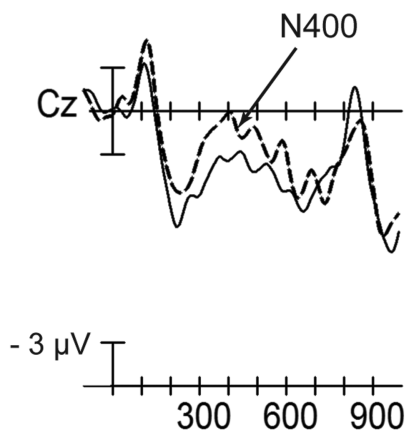

P600 Group

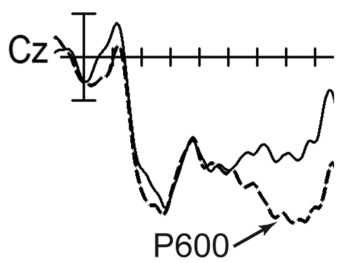

Well-formed verbs Incorrectly inflected verbs

Figure 2 (a) Scatterplot showing the distribution of N400 and P600 effect sizes across learners, where the effect size refers to the voltage difference between the well-formed and incorrectly inflected conditions, averaged across three midline electrodes ( $\mathrm{Fz}, \mathrm{Cz}$, and $\mathrm{Pz}$ ). Each dot represents a data point from a single learner. The solid line shows the best-fit line for the data from the regression analysis. The dashed line represents equal N400 and P600 effect sizes and shows where learners were divided into groups: Individuals above/to the left of the dashed line showed primarily an N400 effect to German verb agreement violations, whereas individuals below/to the right of the dashed line showed primarily a P600 effect. (b) Grand mean ERP waveforms for learners who showed primarily an N400 or primarily a P600 effect to German verb agreement violations. 
progressing through their first year of L2 French instruction and further investigated the role of L1-L2 similarity by contrasting the rate of acquisition for a rule that is shared by the L1 and L2 and a rule that is unique to the L2. As in German and English, French overtly marks subject-verb agreement (a similar rule), but unlike English, French also overtly marks number agreement between a definite determiner and noun (le livre/les livres "the book/the books," a dissimilar rule). ${ }^{4}$ ERPs were recorded from native French speakers $(n=9)$ in a single session and from novice French learners $(n=14)$ in three successive sessions: after approximately 4 weeks (Session 1), 16 weeks (Session 2), and 26 weeks of instruction (Session 3). Native speakers' responses were as expected: agreement violations for both rules elicited P600 responses. For the similar rule, learners' responses showed striking changes through the year of instruction and also marked individual differences associated with learning rate. Verbal agreement anomalies elicited a reliable N400 effect at Session 1, small amplitude differences at Session 2, and a P600 effect at Session 3 (Figure 3a). Further examination of the

A.

Session 1

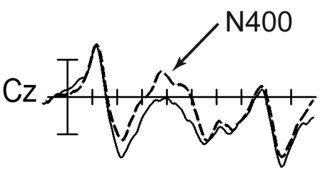

B.
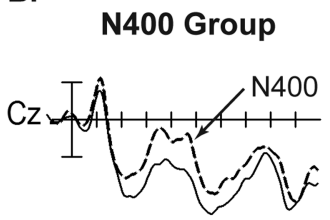

$-3 \mu \mathrm{V}$

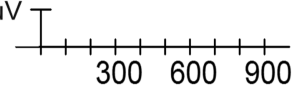

Session 2

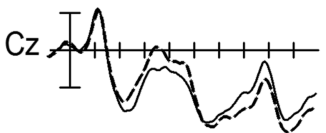

P600 Group

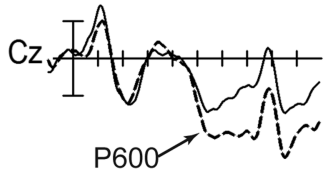

Well-formed verbs

Incorrectly inflected verbs

Figure 3 (a) ERPs to the grammatical (solid line) and ungrammatical (dashed line) French verbal agreement condition recorded during the three successive testing sessions. (b) ERPs, recorded during Session 2, averaged over learners in the N400 group (left) and P600 group (right). 
Session 2 data showed a similar distribution of responses as in the German experiment. A subset of individuals showed primarily an N400 response, whereas a second subset showed primarily a P600 response (Figure $3 b$ ). The effect size of learners' P600, but not N400, during Session 2 was also significantly positively correlated with their d-prime score, showing the same relationship between learning rate and P600 brain response as in the German experiment. For the dissimilar rule (the noun agreement condition), learners' brain responses did not differ significantly between the well-formed and ill-formed stimuli and did not change significantly over the course of the year of instruction.

Results from this study suggest that rule similarity does play a role in the learning rate of L2 grammatical rules. For the verb agreement rule, which is similar in English and French, learners showed sensitivity to grammatical violations after just a few weeks of instruction, although not in a nativelike way. Despite the simplicity and regularity of the French determiner-noun agreement rule, which is dissimilar in English and French, learners showed little neural or behavioral evidence of having acquired the rule despite a full year of instruction. However, one possible confound in attributing the difference in learning rate to L1-L2 differences is that French plural morphology on nouns is largely silent, whereas the majority of the verb agreement contrasts used in this study were phonological realized. In order to follow up on this confound, we systematically investigated the effect of phonological realization on agreement processing. We report findings from these experiments in the following section. The most striking finding in this experiment, however, was the discontinuity in brain responses associated with learning the verb agreement rule: Learners showed a reliable N400 effect to verb agreement violations after just a few weeks of instruction, but by the end of the academic year, the same learners showed a P600 response to the same violations. The individual differences seen during Session 2 also indicate that those who showed faster learning of the rule, indexed by higher behavioral sensitivity, were quicker to progress from the N400 to the P600 stage.

These two experiments investigated the effects of L1-L2 similarity on the acquisition of grammatical rules at the morphosyntactic level. However, grammar is present at multiple levels of language. L1-L2 similarity might also affect the learning of grammatical rules at other levels, such as rules that govern the formation of L2 words. In another longitudinal study, we investigated how adult novice learners of Finnish processed L2 letter strings that either obeyed or violated Finnish vowel harmony (Pitkänen, Tanner, J. McLaughlin, \& Osterhout, 2010). Vowel harmony restricts the distribution of vowels in a Q4 word. Finnish has two opposing vowel classes - back vowels (/u, o, a/) and 
front vowels $(/ y, \varnothing, æ /)$, which never co-occur in a word stem and suffixes of native, noncolloquial words. If the initial vowel of a word is a front vowel, all subsequent vowels must be either front vowels or neutral vowels (/i, e/). If the initial vowel is a back vowel, only back vowels and neutral vowels are permitted (Suomi, McQueen, \& Cutler, 1997). English has no such rule, so vowel harmony constitutes a novel rule for English speakers learning Finnish.

Participants in our experiment included 14 native Finnish speakers and 18 native English speakers enrolled in their first year of Finnish instruction. ERPs were recorded while the participants performed a visual lexical decision task. Learners were tested in three successive sessions (after approximately 2,5 , and 8 months of instruction), whereas native speakers were tested in a single session. The stimuli included Finnish words selected from the learners' textbook (Finnish words; e.g., runo "poem"), orthographically legal, wordlike letter strings (pseudowords, ${ }^{*}$ noru), and vowel harmony violating letter strings (vowel harmony violations, ${ }^{*} k i y n a$ ).

Native Finnish speakers' brain responses clearly discriminated between the different conditions: pseudowords elicited an N400 effect relative to real words (Figure 4a), whereas vowel harmony violations elicited a P600 effect along with an earlier positivity between 150 and $300 \mathrm{~ms}$ (Figure 4b). For the learners, pseudowords elicited a small, but reliable N400 effect in all three sessions (Figure 5a). Brain responses to vowel harmony violations showed striking changes across the year of instruction (Figure 5b). At Session 1,

A.

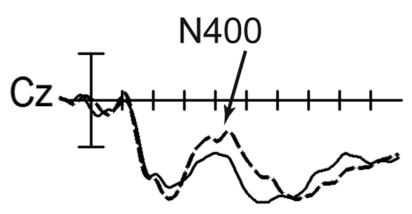

— Finnish words

------ Pseudowords
B.

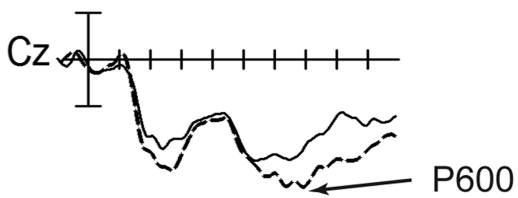

Finnish words

------ Vowel harmony violations

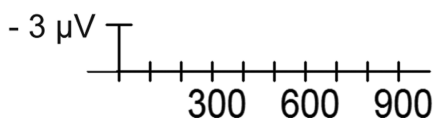

Figure 4 ERPs elicited by (a) Finnish words (solid line) and orthographically legal pseudowords (dashed line) and (b) Finnish words (solid line) and vowel harmony violations (dashed line) for native Finnish speakers. 
A.

\section{Session 1}

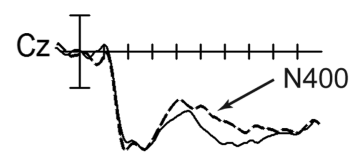

$-3 \mu \mathrm{V}$

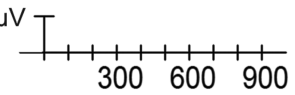

Session 2

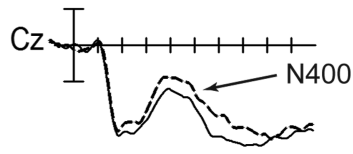

Finnish words

Pseudowords

B.

Session 1

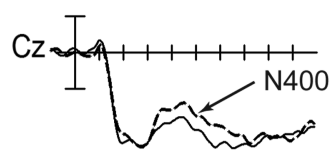

$-3 \mu \mathrm{V}$

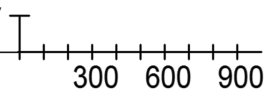

Session 2

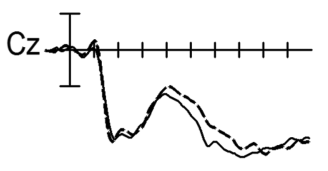

— Finnish words

------ Vowel harmony violations
Session 3

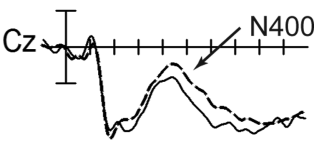
s 
they elicited a reliable N400 effect. At Session 2, no significant effects were found when ERPs were averaged across all learners. However, consistent with the German and French experiments reviewed here, a closer investigation of the individuals' brain responses revealed that a subset of learners showed a larger N400 effect $(n=10)$, whereas a second subset showed a larger P600 effect $(n=8)$ (Figure $5 \mathrm{c})$ and N400 effect sizes were significantly negatively correlated with P600 effect sizes across subjects. At Session 3, vowel harmony violations elicited a robust $\mathrm{P} 600$ effect, similar to the native speakers' responses. Consistent with the other experiments reviewed here, the learners' P600 effect sizes to vowel harmony violations were significantly positively correlated with their d-prime scores in the lexical decision task in Sessions 2 and 3, suggesting that faster learners of the vowel harmony rule show more robust P600 effects. The N400 effects to the pseudowords and vowel harmony violations in Session 1 indicate that learners were able to discriminate words from nonwords after only a short period of instruction (cf. J. McLaughlin, Osterhout, \& Kim, 2004). Given the similarity between the brain responses in the two conditions, it appears that the learners were using the same underlying mechanisms to process these items. Crucially, it is only to the rulelike aspects of Finnish word formation that learners gradually transitioned to a P600 effect, showing the emergence of a second, independent processing stream that operates in parallel with the lexically based stream. This indicates that rules of word formation are also subject to the type of "grammaticalization" of morphosyntactic rules such as agreement. However, contrary to the L2 French study discussed earlier, the results of this experiment show neural sensitivity to an aspect of grammar that is unique to the L2. L1-L2 similarity may differentially affect the rate of grammaticalization for morphosyntactic and word formation rules. Learners showed nativelike brain responses to violations of Finnish vowel harmony within the first year of instruction, whereas 1 year of instruction was not sufficient for learners to grammaticalize (as defined here) the dissimilar morphosyntactic rule in French. This sensitivity may be aided by the regularity of the vowel harmony rule as well as by the relative phonological transparency of the Finnish orthographic system. Moreover, the vowel harmony rule operates only within, rather than across, lexical items.

\section{Effects of Phonological Realization}

It has been suggested that the rate of morphosyntactic learning can be influenced by the covariation between morphology and phonology. Some languages, such as French, have largely silent morphologies, with a many-to-one mapping 
between morphemic inflections and phonemes. For example, in written French, regular verbs have five different inflections for the six verbal persons but only three phonological forms. Additionally, in the vast majority of cases, the plural morpheme $-\mathrm{s}$, which marks plurality on nouns, adjectives, and sometimes pronouns, is phonologically silent (Dubois, 1965). Therefore, some French sentences (such as Il mange du pain "He eats bread" and Ils mangent du pain "They eat bread") are phonologically identical and can be distinguished only with the help of context. Morphological contrasts that are realized in sound, as well as in writing, might be learned more quickly than those that are not. Consistent with this prediction, native speakers of both French (Fayol, Thevenin, Jarousse, \& Totereau, 1999; Largy \& Fayol, 2001; Negro \& Chanquoy, 2000) and Dutch (Frisson \& Sandra, 2002; Sandra, Frisson, \& Daems, 1999) make fewer inflectional errors in written language for morphemes that are phonologically realized than for those that are not. Furthermore, systematic training in French L2 phonological patterns leads to faster learning of gender agreement in English-speaking learners of French than when training emphasizes spelling variations (Arteaga, Gess, \& Herschensohn, 2003).

The effects of phonological realization on morphosyntactic agreement have also been demonstrated using ERPs (Frenck-Mestre et al., 2008, 2009). FrenckMestre and colleagues (2008) examined the effect of phonological realization on the processing of verbal agreement in written French. ERPs were recorded from a group of native French speakers and German-speaking learners of French while they read French sentences. Some of the French sentences were well formed (e.g., Le matin je mange du pain. "In the morning I eat bread."), whereas others contained verbal inflectional errors that were either orally realized (e.g., *Le matin je mangez du pain. "In the morning I eat 2 ndplural bread.") or orally silent (e.g., "Le matin je manges du pain. "In the morning I eat ${ }_{2 n d s i n g}$ bread."). Native French speakers showed a robust P600 to all subject-verb agreement errors, with phonologically realized inflectional errors producing a larger P600 effect than phonologically silent errors. In learners of French, phonologically realized errors produced a robust $\mathrm{P} 600$ response, whereas silent errors produced no significant effects. These results seem to support the idea that the presence of phonological cues plays an important role in the processing and learning of grammatical morphemes. It should be noted, however, that the group of learners used in this study had several years of instruction in their L2 and were living in France and following a university curriculum in the French language at the time of their participation. It remains unclear whether the presence of phonological cues facilitates the learning of morphosyntactic agreement during the earliest stages of L2 acquisition. 
To isolate the effects of phonological realization on morphosyntactic learning, we longitudinally obtained ERP responses to visually presented French sentences from English-speaking novice French learners $(n=18)$ while they engaged in a grammaticality judgment task et al., in preparation). The stim- Q5 uli used in this study were identical to those used by Frenck-Mestre et al. (2008). Learners were tested in three consecutive sessions: after approximately 3 months, 6 months, and 9 months of French instruction-Sessions 1, 2, and 3, respectively. As in our previous studies, the learners showed striking individual differences in their ERP responses. Thus, using the procedure described earlier, we separated the learners into two groups ("N400 group" and "P600"group) based on their ERP responses recorded during the third session. Results for the two groups, for all three sessions, are shown in Figure 6. For the N400 group (Figure 6a), no significant ERP differences were observed between the well-formed and ill-formed sentences during the first two sessions. However, by Session 3, after approximately 9 months of instruction, this group of learners

Session 1

A.
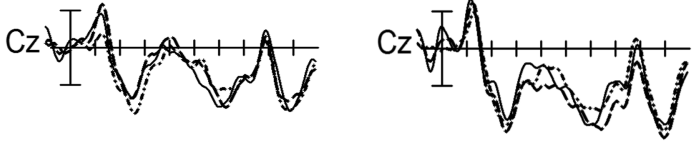

B.
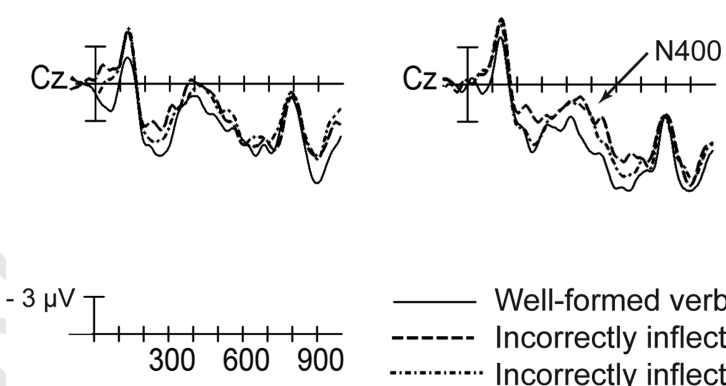

Session 2

Session 3
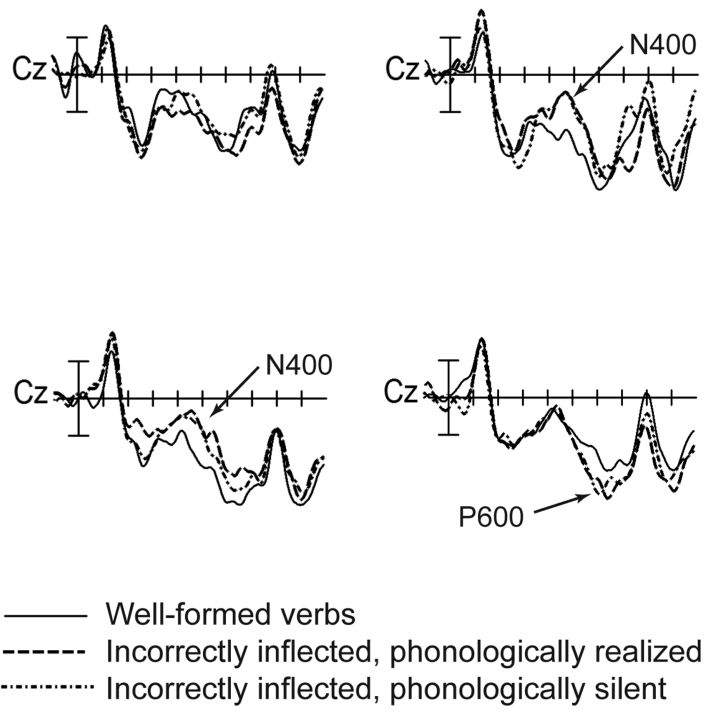

Figure 6 ERPs from the learners in the (a) N400 group and (b) P600 group, recorded during the three testing sessions. ERPs are plotted for the critical words in grammatical French sentences (solid line) and French sentences that contained phonologically realized (dashed line) and phonologically silent (dotted-dashed line) verbal inflectional violations. 
showed an N400 effect to the morphosyntactic errors. By contrast, the P600 group showed no reliable ERP effects during Session 1 and an N400 response to inflectional errors during Session 2, and by Session 3, the N400 effect was replaced by a small P600 effect (Figure 6b). No reliable ERP differences between the phonologically realized and phonologically silent errors were observed during any of the testing sessions for either group.

Although we did not observe an effect of phonological realization in the learners' ERPs, we did see differences in their acceptability judgments to these items. Learners were more accurate at identifying the inflectional errors when those errors were phonologically realized ( $M$ d-prime, averaged across sessions $=2.7, S E=0.21)$ than when they were phonologically silent ( $M \mathrm{~d}$-prime, averaged across sessions $=2.1, S E=0.18$ ). This suggests that perhaps, in our learners, the processing of the orthographic input may not have triggered a simultaneous activation of phonological information, as it seems to have with native speakers and more proficient learners. It is possible that our learners used phonological information later during processing in order to make wellformedness decisions about the sentences. The presence of phonological cues, therefore, does seem to have some effect on the learning of grammatical morphemes in the early stages of acquisition, at least as indexed by the learners' behavioral performance.

The most striking finding, however, is that, as in our previous studies, a subset of learners showed a discontinuous pattern over time in their ERP responses to L2 morphosyntactic anomalies: Early in learning, such anomalies elicited an N400, whereas later in learning these same anomalies elicited a P600 effect. This provides further evidence that learners were progressing though discrete stages of learning, a point we will address in the subsequent section. The lack of an effect of phonological realization on learners' neural responses also seems to suggest that the ERP differences that we observed between the verbal person and determiner-noun agreement rules discussed in the previous section may have been influenced more by L1-L2 similarity than by phonological realization. Thus, the learners' difficulty with French determinernoun number agreement may have been a result of native language influence, as English does not overtly mark this grammatical relation systematically.

\section{Discontinuities in L2 learning}

Several lines of research suggest that learners progress through qualitatively distinct stages as they learn L2 grammar. This research suggests that learners' early grammar (for both L1 and L2 learning) involves item-based schemas 
and formulaic strings that have little or no internal structure; learners eventually decompose these schemas and induce abstract grammatical categories and productive rules (Berman, 1986; B. McLaughlin, 1990; B. McLaughlin \& Heredia, 1996; Myles, Hooper, \& Mitchell, 1998; Tomasello, 2000; Wong Fillmore, 1976; Wray, 2002). Similar arguments have been made for changes in L2 learners' representations of morphologically complex words, which are claimed to be initially memorized as unanalyzed wholes and, with more language experience, eventually decomposed into stem + affix sequences (Zobl, 1998). Similarly, some neurocognitive models dissociate memorized declarative knowledge and productive procedural knowledge, where learners first rely on declarative knowledge and then develop procedural knowledge for processing L2 grammar (Ullman, 2001, 2005; cf. Paradis, 1994, 2004).

The studies reviewed here provide compelling evidence that learners progress through distinct stages of grammatical learning. One advantage of using ERPs over other methods to investigate developmental discontinuities is that ERPs respond differently to anomalies involving grammatical rules and those that do not. Given that N400 amplitude is sensitive to novel words and word sequence probabilities (i.e., the probability of one word following another), one possibility is that learners initially memorize inflected words as unanalyzed wholes and then group salient word sequences into undecomposed strings, or chunks (e.g., that $J e$ is followed by mange, whereas $I l s$ is followed by mangent). At this stage, violations of a grammatical agreement rule result in unfamiliar word combinations (e.g., ${ }^{*}$ Je mangent), thus eliciting an N400 effect. This interpretation, which we have proposed in previous work (Osterhout et al., 2006, 2008; Tanner et al., 2009), is consistent with research suggesting that formulaic chunks play a role in L2 learners' grammatical development (e.g., Myles et al., 1998; Wong Fillmore, 1976; Wray, 2002; Zobl, 1998) and that L2 learners do not decompose morphologically complex words (Neubauer \& Clahsen, 2009; Silva \& Clahsen, 2008). Moreover, this account aligns well with neurocognitive models in which, at early stages of L2 learning, grammatical processing relies on item-based lexical memory stores, rather than rule-based mechanisms (Ullman, 2001, 2005). However, not all of the recent evidence is consistent with such claims. For example, N400 effects to violations of adjective-noun gender agreement have been reported in novice L2 learners (Carrasco \& Frenck-Mestre, 2009; Foucart \& Frenck-Mestre, 2006). It does not seem likely or practical, even given a relatively small vocabulary, that L2 learners are memorizing the various combinations of adjectives and nouns. Additionally, ongoing work in our lab suggests that some process other than chunking may be at play. 
In our lab we are currently investigating lexical decomposition in the early stages of L2 learning. In this experiment we present learners with sentences that contain two types of anomalies: real-word verbal inflectional errors and pseudowords (i.e., letter strings that resemble real words but do not violate the phonological and orthographic rules of the language) that are either correctly inflected (i.e., Ils parnent ${ }_{3 \text { rd plural }}$ ) or incorrectly inflected (i.e., $I_{s}$ parnons ${ }_{1 \text { st plural }}$ ). We are following English-speaking students as they progress through their first year of French instruction. The learners are being tested in two sessions (near the beginning and end of the 9-month instructional period).

Given that N400 amplitude is sensitive to lexical status (Bentin, 1987), we expect both types of pseudowords to elicit an N400 effect relative to wellformed words. Of particular relevance to this discussion is whether the learners' ERP responses to the two pseudoword conditions differ. If, during the initial stages of acquisition, learners memorize unanalyzed chunks, we predict no ERP differences between the two pseudoword conditions, as each pseudoword manipulation would result in equally novel letter sting combinations. However, once learners have induced a morphosyntactic rule, we expect an N400 effect to the correctly inflected pseudowords, but a biphasic response (an N400 followed by a P600) to the incorrectly inflected pseudowords.

Preliminary results from 14 learners are reported here. During the first session, as expected, all learners showed robust N400 effects to pseudowords relative to real words. Contrary to our prediction, however, incorrectly inflected pseudowords elicited larger N400s than correctly inflected pseudowords (Figure 7a). After 9 months of instruction, the learners' ERPs showed marked individual differences. Whereas one subset of learners $(N=6)$ continued to show the same pattern as in Session 1, a second subset of learners $(N=8)$ showed a change in brain response patterns. Although this group continued to show larger N400s to pseudowords relative to words, the two pseudoword conditions did not differ in N400 amplitude. However, the two pseudoword conditions did differ in the P600 window: Incorrectly inflected pseudowords elicited a robust P600 effect (Figure 7b), indicating that these learners may have been applying a morphosyntactic rule to these stimuli.

These results are inconsistent with the claim that during the initial stage of learning, learners memorize salient whole-word sequences. The roots of the pseudowords in each condition were identical; they differed only in the inflectional ending. If the learners were memorizing whole-word combinations, these pronoun-pseudoword sequences should be equally novel. The difference in N400 amplitude between the correctly and incorrectly inflected pseudowords during the first session suggests that under certain conditions - even during the 
A.

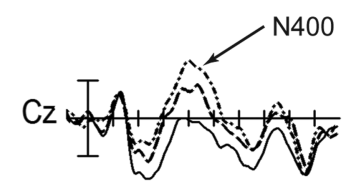

Well-formed verbs

------ Pseudowords, correctly inflected

............ Pseudowords, incorrectly inflected

B.

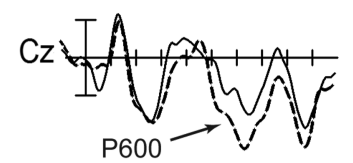

Pseudowords, correctly inflected

------ Pseudowords, incorrectly inflected

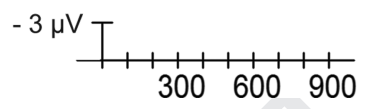

Figure 7 (a) Learners' ERPs to well-formed verbs (solid line) and pseudowords that were either correctly inflected (dashed line) or incorrectly inflected (dotted-dashed line), recorded during Session 1. (b) ERPs averaged over learners in the P600 group for the correctly inflected (solid line) and incorrectly inflected (dashed line) pseudowords recorded during Session 2.

earliest stages of learning - learners were decomposing the inflectional affix from the pseudoword stem.

One interpretation of these preliminary results is that learners are memorizing probabilistic dependencies between nonadjacent morphemes (i.e., the subject pronoun Ils is always followed by the verb ending -ent) rather than whole-word sequences. On this account, the N400 may reflect learners' sensitivity to these dependencies - that is, the probability of occurrence of particular pronoun-verb ending combinations as opposed to the application of a productive rule.

This interpretation seems highly plausible given that recent behavioral research in statistical learning has demonstrated that adults can quickly extract certain kinds of regularities between linguistic elements when there is a high transition probability (Newport \& Aslin, 2004; Saffran, 2001; Saffran, Johnson, Aslin, \& Newport, 1999). This suggests that agreement relations in natural 
language that are strictly regular can be readily acquired using frequency-based learning mechanisms. Much of this work has focused on word learning and the learning of phrase structure rules, not morphosyntactic agreement. However, a similar account seems plausible. What this research does not address is how or if learners go beyond statistically based patterns in the input to inducing productive rules. Taken together, the studies reviewed here clearly demonstrate that such a progression indeed occurs; there are qualitative changes in the neurocognitive mechanisms underlying language processing during the first year of instruction. In the early stages, learners may exploit statistical dependencies in the input as they gradually uncover the underlying structures inherent in the L2 system they are learning. The gradual shift from N400 to P600 responses to grammatical violations may then reflect the induction of a generalized rule from specific regularities in the input.

Regardless of the functional interpretation that one ascribes to the N400 or P600 effect, the most important aspect of our findings is the consistency across studies showing a gradual shift from one type of processing to another in a remarkably short period of time. This qualitative change is robust across experiments, languages, and levels of structure (i.e., lexical vs. sentential). These results suggest that there is a surprising amount of similarity in the developmental trajectories of linguistic knowledge across different levels of language and across different languages, implying that a common mechanism may be responsible for learning disparate rulelike aspects of an L2. We should note, however, that although the discontinuity is present and reproducible, at the moment the functional significance of these stages is uncertain. However, we believe that our suggestions in this regard are consistent with what is currently known.

\section{Final Comments}

The evidence reviewed here suggests several conclusions. First, the native language has an influence on the rate of grammaticalization for L2 morphosyntactic agreement. Although our investigations have not systematically explored every aspect of L1-L2 similarity, we have found evidence that similar agreement rules are grammaticalized relatively quickly, whereas learners show greater difficulty acquiring an agreement rule that is not overtly expressed in their L1. This observation is qualified by our finding that learners quickly grammaticalized the Finnish vowel harmony rule. Second, the presence of phonological cues to morphosyntactic agreement shows somewhat different effects during processing in novice learners versus more advanced learners and native speakers. 
Nonetheless, we found evidence that the phonological status of grammatical morphemes plays a role in the learning of grammatical rules. Further research on the influence of the native language, the level of linguistic structure, and phonological information on grammatical learning should provide a clearer understanding of how and when learners acquire rulelike aspects of their L2.

The most striking finding across all of the studies reviewed here was the clear and consistent change in learners' brain responses to violations of L2 grammatical rules across the first year of instruction. By using a measure that is differentially sensitive to levels of linguistic processing, our research clearly shows that some learners progress through discontinuous stages during grammatical learning. Additionally, because grammatical violations elicit N400 responses, rather than $\mathrm{P} 600$ responses, in the earliest stages of learning, it does not seem that a complete transfer of $\mathrm{L} 1$ grammatical processing resources takes place when acquiring an L2. Rather, we have suggested that inductive learning mechanisms may be responsible for the acquisition of L2 grammatical rules, even when that rule is present in the learner's L1.

We would finally like to comment on the interpretation of null results in the context of L2 research. Some recent L2 research has focused on explaining the presence or absence of the LAN effect in language learners. The LAN features prominently in some recent neurocognitive models of native language processing (Friederici, 1995; Hahne \& Friederici, 1999; Ullman, 2001, 2005); analogously, the lack of LAN effects in some L2 studies has been argued to reflect a corresponding absence of the linguistic process manifested by this effect (Hahne, 2001; Ullman, 2001, 2005) or that L2 learners may be restricted to non-native-like grammatical processes (Clahsen \& Felser, 2006). Others have speculated that biphasic LAN-P600 responses to grammatical anomalies represent the end point of the L2 acquisition process (Steinhauer, White, \& Drury, 2009). These claims rest on the assumption that the LAN is always present during native language processing; however, there are numerous studies of grammatical processing that have failed to show LAN effects in native speakers (e.g., Ainsworth-Darnell et al., 1998; Frenck-Mestre et al., 2008, 2009; Hagoort et al., 1993; Kim \& Osterhout, 2005; McKinnon \& Osterhout, 1996; Osterhout \& Mobley, 1995; Sabourin \& Stowe, 2008). Moreover, in the experiments reported earlier, verb agreement and vowel harmony violations did not elicit LAN effects in any of the native-speaker control groups. Thus, it is difficult to interpret the lack of LAN effects in our learners as evidence of non-native-like processing (see Frenck-Mestre et al., 2009; Osterhout, J. McLaughlin, Kim, Greenwald, \& Inoue, 2004; Osterhout et al., 2006, for a more thorough discussion of these issues). 
Our research highlights the importance of recognizing between-subject variability when interpreting experimental findings, especially with ERPs. In order to achieve the necessary signal-to-noise ratio, ERPs need to be averaged over trials from a given subject and then over all subjects. The more consistent the ERP response is within and across subjects, the more robust and reproducible the results. Increased variability in ERP responses usually leads to a reduction in effect size. Because a greater amount of variability is expected in a group of L2 learners, it is possible that ERP effects may be obscured due to large intersubject variability in the effect's timing and distribution. This is especially likely in effects that are small in amplitude, such as the LAN or those typically seen in novice L2 learners. However, we have demonstrated that by carefully studying this variability, it is also possible to reveal what are in fact systematic differences across subjects. This underscores the problems in interpreting null results in L2 research, as true effects may be obscured by variability, whether it is random or systematic.

\section{Notes}

1 Although there are exceptions to this generalization with highly complex sentences (see Osterhout, Kim, \& Kuperberg, in press, for a fuller discussion of this issue), this generalization holds true under the conditions that we are using with our L2 subjects (i.e., the presentation of relatively simple sentences). Additionally, although the functional significance of the various observed ERP effects remain unknown, the systematic dissociation between N400 and P600 effects still allows us to speculate about the processing strategies used by our L2 learners.

2 The effect size here refers to the amplitude difference between the well-formed and ill-formed conditions.

3 Preliminary analyses from this experiment were previously reported in Osterhout et al. (2004, 2006, 2008).

4 English does mark determiner-noun agreement in other contexts, such as with this/these; however, number agreement within the NP is not marked as systematically in English as in French. Moreover, agreement with the definite determiner the is missing in

\section{References}

Ainsworth-Darnell, K., Shulman, H. G., \& Boland, J. E. (1998). Dissociating brain responses to syntactic and semantic anomalies: Evidence from event-related brain potentials. Journal of Memory and Language, 38, 112-130. 
Ard, J., \& Homburg, T. (1983). Verification of language transfer. In S. M. Gass \& L. Selinker (Eds.), Language transfer in language learning (pp. 157-176). Rowley, MA: Newbury House.

Arteaga, D., Gess, R., \& Herschensohn, J. (2003). Focusing on phonology to teach morphological form in French. Modern Language Journal, 8, 58-70.

Barber, H., Vergara, M., \& Carreiras, M. (2004). Syllable-frequency effects in visual word recognition: Evidence from ERPs. NeuroReport, 15, 545-548.

Bentin, S. (1987). Event-related potentials, semantic processes, and expectancy factors in word recognition. Brain and Language, 31, 308-327.

Bentin, S., McCarthy, G., \& Wood, C. C. (1985). Event-related potentials associated with semantic priming. Electroencephalography and Clinical Neurophysiology, 60, 343-355.

Berman, R. A. (1986). A step-by-step model of language acquisition. In I. Levin (Ed.), Stage and structure: Reopening the debate (pp. 191-219). Norwood, NJ: Ablex.

Birdsong, D. (1992). Ultimate attainment in second language acquisition. Language, 68, 706-755.

Birdsong, D. (1999). Second language acquisition and the critical period hypothesis. Mahwah, NJ: Erlbaum.

Birdsong, D., \& Molis, M. (2001). On the evidence for maturational constraints in second-language acquisition. Journal of Memory and Language, 44, 235-249.

Carrasco, H., \& Frenck-Mestre, C. (2009). Phonology helps in processing grammatical gender: ERP evidence from L1 and L2 French. Paper presented at the CUNY Conference on Human Sentence Processing, University of California, Davis.

Clahsen, H., \& Felser, C. (2006). Grammatical processing in language learners. Applied Psycholinguistics, 27, 3-42.

Dubois, J. (1965). Grammaire structurale du Francais. Paris: Larousse.

Fayol, M., Thevenin, M., Jarousse, J. P., \& Totereau, C. (1999). From learning to teaching to learn French written morphology. In T. Nunes (Ed.), Learning to read: An integrated view from research and practice (pp. 43-64). Dordrecht: Kluwer.

Foucart, A., \& Frenck-Mestre, C. (2006). Processing of adjectives in French as a first and second language: Evidence from ERPs. Paper presented at the CUNY Conference on Human Sentence Processing, New York.

Franceschina, F. (2005). Fossilized second language grammars: The acquisition of grammatical gender. Amsterdam: Benjamins.

Frenck-Mestre, C., Foucart, A., Carrasco, H., \& Herschensohn, J. (2009). Processing of grammatical gender in French as a first and second language. In L. Roberts, D. Véronique, A. Nilsson, \& M. Tellier (Eds.), Eurosla yearbook 9 (pp. 76-106). Amsterdam: Benjamins.

Frenck-Mestre, C., Osterhout, L., McLaughlin, J., \& Foucart, A. (2008). The effect of phonological realization of inflectional morphology on verbal agreement in French: Evidence from ERPs. Acta Psychologica, 128, 528-536. 
Friederici, A. D. (1995). The time course of syntactic activation during language processing: A model based on neuropsychological and neurophysiological data. Brain and Language, 50, 259-281.

Frisson, S., \& Sandra, D. (2002). Homophonic forms of regularly inflected verbs have their own orthographic representations: A developmental perspective on spelling errors. Brain and Language, 81, 545-554.

Hagoort, P., Brown, C. M., \& Groothusen, J. (1993). The syntactic positive shift as an ERP measure of syntactic processing. Language and Cognitive Processes, 8 , 439-484.

Hahne, A. (2001). What's different in second-language processing? Evidence from event-related brain potentials. Journal of Psycholinguistic Research, 30, 251-266.

Hahne, A., \& Friederici, A. D. (1999). Eletrophysiological evidence for two steps in syntactic analysis: Early automatic and late controlled processes. Journal of Cognitive Neuroscience, 11, 194-205.

Han, Z.-H., \& Odlin, T. (Eds.). (2006). Studies of fossilization in second language acquisition. Clevedon, UK: Multilingual Matters.

Hawkins, R., \& Franceschina, F. (2004). Explaining the acquisition and non-acquisition of determiner-noun gender concord in French and Spanish. In P. Prévost \& J. Paradis (Eds.), The acquisition of French in different contexts (pp. 175-205). Amsterdam: Benjamins.

Hirsh-Pasek, K., \& Golinkoff, R. (Eds.). (1996). The origins of grammar: Evidence from early language comprehension. Cambridge, MA: MIT Press.

Hopp, H. (2007). Ultimate attainment at the interfaces in second language acquisition: Grammar and processing. Unpublished doctoral dissertation, University of Groningen, Groningen, The Netherlands.

Hyltenstam, K., \& Abrahamsson, N. (2003). Maturational constraints in SLA. In C. J. Doughty \& M. H. Long (Eds.), The handbook of second language acquisition (pp. 539-588). Malden, MA: Blackwell.

Inoue, K., \& Osterhout, L. (2010). Sentence processing as a neural tug-of-war. Manuscript in preparation.

Jiang, N. (2004). Morphological insensitivity in second language processing. Applied Psycholinguistics, 25, 603-634.

Jiang, N. (2007). Selective integration of linguistic knowledge in adult second language learning. Language Learning, 57, 1-33.

Johnson, J. S., \& Newport, E. L. (1989). Critical period effects in second language learning: The influence of maturational state on the acquisition of English as a second language. Cognitive Psychology, 21, 60-99.

Kim, A., \& Osterhout, L. (2005). The independence of combinatory semantic processing: Evidence from event-related potentials. Journal of Memory and Language, 52, 205-225. 
Koda, K. (1988). Cognitive process in second language reading: Transfer of L1 reading skills and strategies. Second Language Research, 4, 133-155.

Kutas, M., \& Hillyard, S. A. (1980). Reading senseless sentences: Brain potentials reflect semantic anomaly. Science, 207, 203-205.

Kutas, M., \& Hillyard, S. A. (1984). Brain potentials during reading reflect word expectancy and semantic association. Nature, 307, 161-163.

Lardiere, D. (2007). Ultimate attainment in second language acquisition: A case study. Mahwah, NJ: Erlbaum.

Largy, P., \& Fayol, M. (2001). Oral cutes improve subject-verb agreement in written French. International Journal of Psychology, 36, 121-131.

MacWhinney, B. (1997). Second language acquisition and the Competition Model. In A. M. B. De Groot \& J. F. Kroll (Eds.), Tutorials in bilingualism: Psycholinguistic perspectives (pp. 113-142). Mahwah, NJ: Erlbaum.

MacWhinney, B. (2005). A unified model of language acquisition. In J. F. Kroll \& A. M. B. De Groot (Eds.), Handbook of bilingualism: Psycholinguistic approaches (pp. 49-67). Oxford: Oxford University Press.

McKinnon, R., \& Osterhout, L. (1996). Constraints on movement phenomena in sentence processing: Evidence from event-related brain potentials. Language and Cognitive Processes, 11, 495-523.

McLaughlin, B. (1990). Restructuring. Applied Linguistics, 11, 113-128.

McLaughlin, B., \& Heredia, R. (1996). Information-processing approaches to research on second language acquisition and use. In W. C. Ritchie \& T. K. Bhatia (Eds.), Handbook of second language acquisition (pp. 213-228). San Diego, CA: Academic Press.

McLaughlin, J., Osterhout, L., \& Kim, A. (2004). Neural correlates of second-language word learning: Minimal instruction produces rapid change. Nature Neuroscience, 7, 703-704.

Myles, F., Hooper, J., \& Mitchell, R. (1998). Rote or rule? Exploring the role of formulaic language in classroom foreign language learning. Language Learning, 48, 323-364.

Negro, I., \& Chanquoy, L. (2000). Subject-verb agreement with present and imperfect tenses: A developmental study from 2 nd to 7 th grade. European Journal of Psychology of Education, 15, 113-134.

Neubauer, K., \& Clahsen, H. (2009). Decomposition of inflected words in a second language: An experimental study of German participles. Studies in Second Language Acquisition, 31, 403-435.

Neville, H. J., Nicol, J., Barss, A., Forster, K., \& Garrett, M. (1991). Syntactically based sentence processing classes: Evidence from event-related brain potentials. Journal of Cognitive Neuroscience, 3, 151-165.

Newport, E. L., \& Aslin, R. N. (2004). Learning at a distance: I. Statistical learning of non-adjacent dependencies. Cognitive Psychology, 48, 127-162. 
Odlin, T. (1989). Language transfer. Cambridge: Cambridge University Press.

Osterhout, L., Frenck-Mestre, C., McLaughlin, J., Tanner, D., \& Herschensohn, J. (2010). Morphosyntactic processing in the early stages of second language acquisition: Evidence from event-related potentials. Manuscript in preparation.

Osterhout, L., \& Holcomb, P. J. (1992). Event-related brain potentials elicited by syntactic anomaly. Journal of Memory and Language, 31, 785-806.

Osterhout, L., Holcomb, P. J., \& Swinney, D. A. (1994). Brain potentials elicited by garden-path sentences: Evidence for the application of verb information during parsing. Journal of Experimental Psychology: Learning, Memory, and Cognition, $28,786-803$.

Osterhout, L., Kim, A., \& Kuperberg, G. (in press). The neurobiology of sentence comprehension. In M. Spivey, M. Joannisse, \& K. McRae (Eds.), The Cambridge handbook of psycholinguistics. Cambridge: Cambridge University Press.

Osterhout, L., McLaughlin, J., Kim, A., Greenwald, R., \& Inoue, K. (2004). Sentences in the brain: Event-related potentials as real-time reflections of sentence comprehension and language learning. In M. Carreiras \& C. Clifton, Jr. (Eds.), The on-line study of sentence comprehension: Eyetracking, ERPs, and beyond (pp. 271-308). New York: Psychology Press.

Osterhout, L., McLaughlin, J., Pitkänen, I., Frenck-Mestre, C., \& Molinaro, N. (2006). Novice learners, longitudinal designs, and event-related potentials: A means for exploring the neurocognition of second language processing. Language Learning, 56(Suppl. 1), 199-230.

Osterhout, L., \& Mobley, L. (1995). Event-related brain potentials elicited by failure to agree. Journal of Memory and Language, 34, 739-773.

Osterhout, L., Poliakov, A., Inoue, K., McLaughlin, J., Valentine, G., Pitkänen, I., et al. (2008). Second-language learning and changes in the brain. Journal of Neurolinguistics, 21, 509-521.

Paradis, M. (1994). Neurolinguistic aspects of implicit and explicit memory: Implications for bilingualism and SLA. In N. C. Ellis (Ed.), Implicit and explicit learning of languages (pp. 393-419). London: Academic Press.

Paradis, M. (2004). A neurolinguistic theory of bilingualism. Amsterdam: Benjamins.

Pitkänen, I., Tanner, D., McLaughlin, J., \& Osterhout, L. (2010). Use it or lose it: Second language attrition in the brain looks like acquisition in reverse. Manuscript in preparation.

Rossi, S., Gugler, M. F., Friederici, A. D., \& Hahne, A. (2006). The impact of proficiency on syntactic second-language processing of German and Italian: Evidence from event-related potentials. Journal of Cognitive Neuroscience, 18, 2030-2048.

Rossi, S., Gugler, M. F., Hahne, A., \& Friederici, A. D. (2005). When word category information encounters morphosyntax: An ERP study. Neuroscience Letters, 384, $228-233$ 
Ryan, A., \& Meara, P. (1991). The Case of the invisible vowels: Arabic speakers reading English words. Reading in a Foreign Language, 7, 531-540.

Sabourin, L., \& Haverkort, M. (2003). Neural substrates of representation and processing of a second language. In R. van Hout, A. Hulk, F. Kuiken, \& R. Towell (Eds.), The Lexicon-syntax interface in second language acquisition (pp. 175-195). Amsterdam: Benjamins.

Sabourin, L., \& Stowe, L. A. (2008). Second language processing: When are first and second languages processed similarly? Second Language Research, 24, 397-430.

Sabourin, L., Stowe, L. A., \& de Haan, G. J. (2006). Transfer effects in learning a second language grammatical gender system. Second Language Research, 22, 1-29.

Saffran, J. R. (2001). The use of predictive dependencies in language learning. Journal of Memory and Language, 44, 493-515.

Saffran, J. R., Johnson, E. K., Aslin, R. N., \& Newport, E. L. (1999). Statistical learning of tone sequences by human infants and adults. Cognition, 70, 27-52.

Sandra, D., Frisson, S., \& Daems, F. (1999). Why simple verb forms can be so difficult to spell: The influence of homophone frequency and distance in Dutch. Brain and Language, 68, 277-283.

Schwartz, B. D., \& Sprouse, R. (1996). L2 cognitive states and the full transfer/full access model. Second Language Research, 12, 40-72.

Silva, R., \& Clahsen, H. (2008). Morphologically complex words in L1 and L2 processing: Evidence from masked priming experiments in English. Bilingualism: Language and Cognition, 11, 1-16.

Singleton, D., \& Lengyel, Z. (Eds.). (1995). The age factor in second language acquisition. Clevedon, UK: Multilingual Matters.

Steinhauer, K., White, E. J., \& Drury, J. E. (2009). Temporal dynamics of late second language acquisition: Evidence from event-related brain potentials. Second Language Research, 25, 13-41.

Suomi, K., McQueen, J. M., \& Cutler, A. (1997). Vowel harmony and speech segmentation in Finnish. Journal of Memory and Language, 36, 422-444.

Tanner, D., \& Osterhout, L. (2010). Morphosyntactic development in second language learners. Manuscript in preparation.

Tanner, D., Osterhout, L., \& Herschensohn, J. (2009). Snapshots of grammaticalization: Differential electrophysiological responses to grammatical anomalies with increasing L2 exposure. In J. Chandlee, M. Franchini, S. Lord, \& G-M. Rheiner (Eds.), Proceedings of the 33rd Boston University conference on language development (pp. 528-539). Somerville, MA: Cascadilla Press.

Tokowicz, N., \& MacWhinney, B. (2005). Implicit and explicit measures of sensitivity to violations in second language grammar: An event-related potential investigation. Studies in Second Language Acquisition, 27, 173-204.

Tomasello, M. (2000). The item-based nature of children's early syntactic development. Trends in Cognitive Sciences, 4, 156-163. 
Ullman, M. T. (2001). The neural basis of lexicon and grammar in first and second language: The declarative/procedural model. Bilingualism: Language and Cognition, 4, 105-122.

Ullman, M. T. (2005). A cognitive neuroscience perspective on second language acquisition: The declarative/procedural model. In C. Sanz (Ed.), Mind and context in adult second language acquisition (pp. 141-178). Washington, DC: Georgetown University Press.

Vainikka, A., \& Young-Scholten, M. (1996). Gradual development of L2 phrase structure. Second Language Research, 12, 7-39.

White, L. (2003). Second language acquisition and Universal Grammar. Cambridge: Cambridge University Press.

Wong Fillmore, L. (1976). The second time around: Cognitive and social strategies in second language acquisition. Unpublished doctoral dissertation, Stanford University, Stanford, CA.

Wray, A. (2002). Formulaic language and the lexicon. Cambridge: Cambridge University Press.

Zobl, H. (1998). Representational changes: From listed representations to independent representations of verbal affixes. In M.-L. Beck (Ed.), Morphology and its interfaces in second language knowledge (pp. 339-371). Amsterdam: Benjamins. 


\section{Queries}

Q1 Author: Please update Tanner \& Osterhout, 2010, throughout the text and in the References.

Q2 Author: Please update Inoue \& Osterhout, 2010, throughout the text an in the References.

Q3 Author: Please update Osterhout et al., 2010, throughout the text and in the References.

Q4 Author: Please update Pitkanen et al., 2010, throughout the text and in the References.

Q5 Author: Please provide the complete reference.

Q6 Author: Please update Osterhout et al., in press, throughout the text and in the References.

Q7 Author: Final sentence is incomplete.

Q8 Author: Please provide the month of the conference.

Q9 Author: Please provide the month of the conference. 